\title{
The Relationship Between Quality of Life and Attitudes Toward Barriers in the Leisure Time of Physical Education Students of Adıyaman University
}

\author{
Ümit Yetiş \\ Correspondence: Ümit Yetiş, Adiyaman University, School of Physical Education and Sport, Turkey.
}

Received: May 4, $2018 \quad$ Accepted: June 12, $2018 \quad$ Online Published: June 15, 2018

doi:10.11114/jets.v6i4a.3368 URL: https://doi.org/10.11114/jets.v6i4a.3368

\begin{abstract}
The purpose of this study was to investigate the relationship between quality of life and attitudes toward barriers to leisure time in Adiyaman University of Physical Education in Turkey. The study also examined the differences in quality of life and attitudes toward barriers to the leisure time of Adiyaman University students in Turkey. A standard questionnaire (ÜNIVERSITE YAŞAM KALITESII ÖLÇEĞİ) was used to measure the quality of life students. The standard questionnaire (BOŞ ZAMAN ENGELLERİ ÖLÇEĞİ) was used to measure the attitude to the barriers to leisure time of students. Reliability of the questionnaires was evaluated using Cronbach's alpha test, the quality of life questionnaire of students was 0.82 and the leisure barrier questionnaire was 0.79 . The questionnaires were distributed among the statistical sample (181 students of Adiyaman University of Physical Education in Turkey). The results showed that there is a significant negative relationship between quality of life and attitudes towards the obstacles in leisure time of the Adiyaman University of Physical Education students in Turkey. The correlation coefficient between two variables was 0.63. Also, there was a significant difference in the quality of life and attitudes toward barriers to leisure time among Adiyaman Universidad students in Turkey. Male students had a higher quality of life, and female students had more obstacles in spending their leisure time.
\end{abstract}

Keywords: quality of life, leisure, obstacles, student, Adiyaman Universidad Turkey

\section{Introduction}

\subsection{Introduction the Problem}

One of the areas that represents the everyday life and represents strength and resistance in human life is a leisurely arena. Leisure is an area where human freedom and freedom are more applicable in that field. Consequently, unlike work or education that requires more discipline, there is a good place to resist cultural practices and to create new routines and practices. Therefore, they say that leisure can create culture and reveal the identity of individuals (Bradley \& Inglis, 2012). Some scholars believe that the phenomenon of leisure exists throughout the history of human life, and not at a specific time. But others consider leisure as a phenomenon that is related to industrial civilization and believes that it has two specific characteristics and conditions that are: 1 not influenced by compulsory ceremonies and cultural and social requirements, but by the will and authority of the individual. 2. Other essential activities of everyday life, such as eating, are different (Astrid N, Thuen, 2002). If these two conditions are valid, there is no survival of pre-industrial societies because people have been subject to social-cultural requirements in their pursuit of leisure, such as recreation and entertainment. The reality is that the existence and importance of it has been the result of the growth of industry and the result of consumer society. Leisure activities today are so important that they are even considered as the mirror of community culture. This means that how people spend their leisure time in a community largely reflects the characteristics of the culture of that society, and from this point of view, an attempt to identify how leisure time is important in a community or social group (Green et al., 2006). Leisure time cannot be equally important for different social groups, for example, for young people or leisure students, can affect their academic performance and their educational life. Leisure time for students has many barriers that can affect the facilities and benefits of leisure time. These obstacles themselves are undoubtedly influenced by various factors and variables, including the conditions and qualities of student life. Today, educational institutions are important variables that are related to feelings, affection and satisfaction of students, and their quality of life. Quality of life is a word that does not have the same definition; although people instinctively understand the meaning of it easily, this concept is not the same for all of them. Since, like other variables, measuring it requires a comprehensive definition of it, it has always been attempted to provide a proper definition for it. Many studies do not provide a definition of quality of life. This is either due to the very simple 
definition of it, or because of the complexity of the concept, it avoids its definition, while it is expected that there will be no consensus on the definition of this term. In related research, this concept and dimensions are considered to be clearly defined. Today, issues related to the quality of life are widely discussed in various scientific disciplines, which is why despite the many definitions of this concept, none of the existing definitions found general acceptance (Harrison \& Stuifbergen, 2006). What is important in this definition is that it can be distinguished between this concept and other related concepts such as goodness, health, life satisfaction, and hope. There are different opinions about quality of life. Some researchers believe that it can be called "quality of life" only if it is measured in several aspects of health. Some also believe that a single definition that applies at all stages of a disease or in different societies, there is no such thing as the concept; most scholars agree that quality of life considers positive and negative truths of life alongside each other and has several dimensions. On the other hand, they are considered as a subjective and dynamic concept. Subjective in the sense that it must be determined by the person himself, according to him and not an alternative, and dynamically, that is, will change over time and therefore it is necessary to be measured in a period of time. Although the subjectivity of quality of life domains is not enough for some scientists, some scholars believe that each of the domains of quality of life should be capable of being both mentally and in form Objective measurable.

This group believes that mental judgment, although necessary, is not enough. It is important that in any research relating to quality of life, its definition be clarified by the researcher (Liu et al., 2013). In general, one of the most significant definitions of quality of life is the definition provided by the World Health Organization. According to the WHO, quality of life is the perception of individuals from their position in life in terms of culture, value system in which they live, their goals, expectations, standards and priorities. Therefore, a subject is completely mental and not visible by others and is based on understanding people from different aspects of life (Susniene \& Jurkauskas, 2009).

It seems that understanding students about their position in life in terms of culture, the value system in which they live, their goals, expectations, standards and priorities can be influenced by their attitude toward barriers to leisure time. Therefore, in this article, we try to investigate the relationship between quality of life and attitudes toward barriers to leisure time in Adiyaman University of Physical Education students in Turkey.

\section{Method}

The purpose of this research is applied in terms of type of method, descriptive and correlation. Therefore, in terms of data collection method, the research method is a survey strategy.

\subsection{Participants}

The statistical population of this study is all Physical Education students of the Adiyaman University in Turkey, in number of 340, and a sample size of 181 was determined using the Morgan table.

\subsection{Sampling Procedures}

The statistical sample was selected by simple random sampling from members of the statistical community. To measure the quality of life of students, a standard questionnaire (ÜNIVERSITE YAŞAM KALİTESİ ÖLÇEĞI) and standard questionnaire (BOŞ ZAMAN ENGELLERİ ÖLÇEĞİ) was used to measure the variable of attitude to barriers to leisure time of students. Cronbach's alpha test was used to measure reliability. The alpha coefficient for the quality of life questionnaire was 0.82 and the leisure-time barrier questionnaire was 0.79 .

\section{Results}

Table 1. The Results of Students 'Attitude toward Barriers to Leisure Time with Students' quality

\begin{tabular}{|c|c|c|}
\hline & Statistics & Students 'attitude toward barriers to leisure time \\
\hline \multirow{3}{*}{ Students' quality of life } & Pearson Correlation Coe. & $-{ }^{* *} 0.63$ \\
\hline & Sig. & 0.000 \\
\hline & $\mathrm{N}$ & 181 \\
\hline
\end{tabular}

$* *$ Significance of the test at a significant level of 0.01

According to the results of the above table, we can say that there is a significant negative relationship between quality of life and attitudes toward barriers to leisure time in Adiyaman University of Physical Education students in Turkey. The correlation coefficient between two variables is also -0.63 . 
Table 2. Differences in the quality of life of male and female students

\begin{tabular}{lllllllll}
\hline & Gender & $\mathrm{N}$ & Stand. dev. & M & M. diff. & T & df & Sig. \\
\hline quality of life & Girls & 79 & 0.437 & 3.11 & 0.31 & 3.17 & 179 & 0.000 \\
of students & Boys & 102 & 0.409 & 3.42 & & & & \\
\hline
\end{tabular}

According to the results of the table, we can say that the average quality of life of male students is higher than the average quality of life of female students. That is, male students had better quality of life than female students.

Table 3. Attitudes toward barriers to leisure

\begin{tabular}{lllllllll}
\hline & Gender & $\mathrm{N}$ & Stand. dev. & M & M. diff. & T & df & Sig. \\
Attitudes & Girls & 79 & 0.421 & 3.37 & 0.28 & 2.86 & 179 & 0.012 \\
toward barriers to leisure & Boys & 102 & 0.442 & 3.09 & & & & \\
\hline
\end{tabular}

According to the results of the table, it can be said that the mean attitude to barriers to leisure time of female students is more than the average attitude toward barriers to leisure time of male students. That is, female students have more obstacles than their male students to spending their leisure time.

\section{Conclusion}

In this study, the relationship between quality of life and attitudes toward barriers in leisure time of Adiyaman University of Physical Education students in Turkey was studied. Also, differences in quality of life and attitudes toward barriers in leisure time among the physical education students of Adiyaman University of Turkey were reviewed.

The results showed that there is a significant negative relationship between quality of life and attitudes toward barriers to leisure time in Adiyaman University of Physical Education students in Turkey. In explaining this, we can say that, the quality of life of students, in other words, "their perception of their position in life in terms of culture, the system of value in which they live,

Their goals, expectations, standards and priorities "can be seen in their attitudes to barriers to spending leisure time, such as;" feeling tired of leisure activities, feeling afraid of hurting in leisure activities, health problems, feeling insecure, not being happy in the social setting, lack of someone to teach you how to use leisure, lack of equipment and facilities, crowded places, inappropriate services, remote locations and services available for leisure Leisure, lack of adequate material facilities, lack of leisure time and incompatibility of programs".

The results showed that there is a significant difference between the quality of life among physical education male and female students of Adiyaman University of Turkey. As the average difference between the two groups is clear, the average quality of life of male students is higher than the average quality of life for female students. That is, male students have a better quality of life than female students, and "their perception of their position in life is in terms of culture, the value system in which they live, their goals, expectations, standards and priorities."

The results showed that there was a significant difference between attitudes towards leisure barriers among the students of physical education in Adiyaman University. According to the difference between the mean and the mean of the two groups,

The average attitude to barriers to the leisure of female students is more than the average attitude toward barriers to leisure time for male students, which is also the result of this difference.

That is, female students have more obstacles than male students, such as "feeling tired of leisure activities, feeling afraid of harming leisure activities, having health problems, feeling insecure, not being happy in social settings, There was no one to teach how to use leisure time, lack of equipment and facilities, crowded places, inappropriate services, the lack of places and services available for leisure, lack of adequate material facilities, lack of free time and incompatibility of the program "To spend their leisure time.

\section{References}

Astrid, N., \& Thuen, F. (2002). School journeys and leisure activities in rural and urban adolescents in Norway, Health Promot. Int., 17(1), 21-30. https://doi.org/10.1093/heapro/17.1.21

Bradley, G. L., \& Inglis. B. C. (2012). Adolescent leisure dimensions, psychosocial adjustment, and gender effects. Journal of Adolescence, 1-10. https://doi.org/10.1016/j.adolescence.2012.03.006

Green, G. T., Ken, C. H., Betz, C. J., \& Distefano, C. (2006). Construction and Validation of the National Survey on Recreation and the Environment's Lifestyles Scale, Journal of Leisure Research, 38(4), 513-535. 
https://doi.org/10.1080/00222216.2006.11950090

Harrison, T. C., \& Stuifbergen, A. K. (2006). Life purpose: Effect on functional decline and quality of life in polio survivors. Rehabilitation Nursing, 31, 149-154. https://doi.org/10.1002/j.2048-7940.2006.tb00379.x

Liu, L., Setse, R., Grogan, R., Powe, N. R., \& Nicholson, W. K. (2013). The effect of depression symptoms and social support on blackwhite differences in health-related quality of life in early pregnancy: the health status in pregnancy (HIP) study. BMC Pregnancy Childbirth. https://doi.org/10.1186/1471-2393-13-125

Susniene, D., \& Jurkauskas, A. (2009). The concepts of quality of life and happiness - correlation and differences. Work Humanism, 3, 58-66.

\section{Copyrights}

Copyright for this article is retained by the author(s), with first publication rights granted to the journal.

This is an open-access article distributed under the terms and conditions of the Creative Commons Attribution license which permits unrestricted use, distribution, and reproduction in any medium, provided the original work is properly cited. 